\title{
Synthesis and Characterization and Thermal Decomposition Kinetics of Poly (quinoline)-Copper Composite
}

\author{
Ali Bilici ${ }^{1}$, Ruhiye Nilay Tezel ${ }^{2}$, İsmet Kaya ${ }^{1}$, Fatih Doğan $^{3 *}$ \\ ${ }^{1}$ Department of Chemistry, Faculty of Sciences and Arts, Çanakkale Onsekiz Mart University, 17020, Çanakkale, \\ Turkey alibilici66@ hotmail.com; ikaya@ hotmail.com \\ ${ }^{2}$ Lapseki Vocational School, Çanakkale Onsekiz Mart University, 17020, Lapseki, Çanakkale, Turkey \\ nilaytezel@comu.edu.tr \\ ${ }^{3}$ Secondary Science and Mathematics Education, Faculty of Education, Çanakkale Onsekiz Mart University, 17100, \\ Çanakkale, Turkey*fatihdogan@comu.edu.tr \\ Received: 9 February 2018 \\ Accepted: 15 May 2018 \\ DOI: $10.18466 /$ cbayarfbe. 393015
}

\begin{abstract}
In here, chemical oxidative synthesis of a new poly(quinoline)-copper composite was given in one-step pathway. To obtain composite, the copper sulphate and 2-amino-8-quinolinol were used as oxidant and monomer, respectively. The oxidation product obtained was characterized by FTIR, UV-Vis, thermogravimetry (TG), photoluminescence (PL), SEM-EDX, TEM analysis and solid state conductivity measurements. SEM observations exhibited the presence of a plate-like heterogeneous morphology. Rod like structures was revealed from TEM images. TEM studies also indicated that the copper nanoparticles were almost uniformly distributed on polymer. The thermal decomposition kinetics of oxidation product were also studied. For this, the different methods such as Coats-Redfern, Flynn-Wall-Ozawa, Tang and KissingerAkahira-Sunose were used.

Keywords: Oxidative Polymerization, Composite, Quinoline, Thermal Analysis, Decomposition Kinetic.
\end{abstract}

\section{Introduction}

After the work of Stille and his colleagues [1], many studies have been performed for synthesis, characterization and different applications of polyquinolines [2]. Their high thermal and mechanical stability, low dielectric constant and interesting optical, electrical nature make these polymers the focus of attention [2]. Due to these properties, they have a wide range of usage including OLED, organic photovoltaic and chemosensor applications [2, 3]. The Freandliar reaction, Pd-catalyzed coupling reaction as well as chemical and electrochemical oxidation techniques are well-known methods for production of these polymers $[2,4]$. Chemical oxidation is one of the effective protocols to obtain polyaromatics. The procedure is simple and reactions are often performed out in ambient conditions. Besides, the high degree of conversion can be achieved [5]. To date, some quinoline composite materials have been prepared by chemical oxidation. For example, the composites of 3-amino quinoline [6, 7], 5-amino quinoline [8] and 6-amino quinoline [9] were prepared by using palladium, gold and copper salts, respectively.

In here, the preparation and characterization of new quinoline based composite $(\mathrm{AQP} / \mathrm{Cu})$ were presented. For this, 2-amino-8-quinolinol (AQ) was used as monomer and copper sulphate solution was used as oxidant. The physical and chemical characterizations of oxidation product were given. The thermal decomposition kinetics of $\mathrm{AQP} / \mathrm{Cu}$ were also investigated.

\section{Materials and Methods \\ 2.1. Materials}

The solvents and chemicals (analytical grade) used in this study were supplied from Sigma Chemical Company and used as received. A stock solution used in the synthesis was prepared by dissolving $1.33 \mathrm{~g} \mathrm{CuSO}_{4} .5 \mathrm{H}_{2} \mathrm{O}$ in 100 $\mathrm{mL}$ methanol.

\subsection{Synthesis of $\mathrm{AQP} / \mathrm{Cu}$}

The previous work was followed for the synthesis of $\mathrm{AQP} / \mathrm{Cu}$ [10]. For this, at first, methanol solution of monomer was prepared $(0.2 \mathrm{~g} / 10 \mathrm{~mL})$ and then a stock solution $(1 \mathrm{~mL})$ was added to monomer solution drop by drop. Throughout the oxidant addition, the yellow colored solution turned into green, gradually and turbidity was observed. The resulting precipitates were gathered at the bottom of reaction flask. After filtration, the precipitates obtained were washed with distilled water and dried on vacuum oven.

\subsection{Characterization techniques}

Perkin Elmer FT-IR Spectrum One and Perkin Elmer Lambda 25 were used for FTIR and UV-Vis analysis, respectively. Perkin Elmer Diamond Thermal Analysis was used for thermal analysis (between $15^{\circ}-1000{ }^{\circ} \mathrm{C}$, in 
$\mathrm{N}_{2}$, rate $5-20{ }^{\circ} \mathrm{C} \min ^{-1}$ ). The fluorescent measurements were conducted using Schimadzu RF-5301PC spectrofluorophotometer (slit width: 5nm). JEOL JSM7100F Schottky field emission SEM instrument was used to acquire the surface morphology of $\mathrm{AQP} / \mathrm{Cu}$. TEM images were acquired by using a JEOL TEM-1400 Plus microscope. Methanol was used for suspension of $\mathrm{AQP} / \mathrm{Cu}$ and then it was dispersed, ultrasonically. The measurements were recorded using this suspension prepared $(2 \mathrm{~mL})$. Solid state electrical conductivity of $\mathrm{AQP} / \mathrm{Cu}$ was measured using a Keithley 2400 electrometer, in the pellet form. For this, powdery sample was exposed to a hydraulic press up to $1680 \mathrm{~kg} \mathrm{~cm}^{-2}$ and then pellet obtained was exposed to iodine vapors at atmospheric pressure in a desiccator at room temperature [9].

\section{Results and Discussion}

AQ is a derivate compound of 3-aminoquinoline (3AQ) and 6-aminoquinoline (6AQ). The oxidation of 3AQ [6,7] and 6AQ [9] were accomplished by using palladium acetate and copper sulphate solutions in one step. In the each study, the composite materials composed of core (metal)-shell (polymer) hallows were obtained. The copper sulphate is one of the effective oxidizing agents used in organic reactions [11]. In here, methanol solution of copper sulphate was used for oxidizing of AQ. As a result of oxidation reaction, green colored precipitated were obtained with high yield (92\%). The general reaction scheme is given in Figure 1.

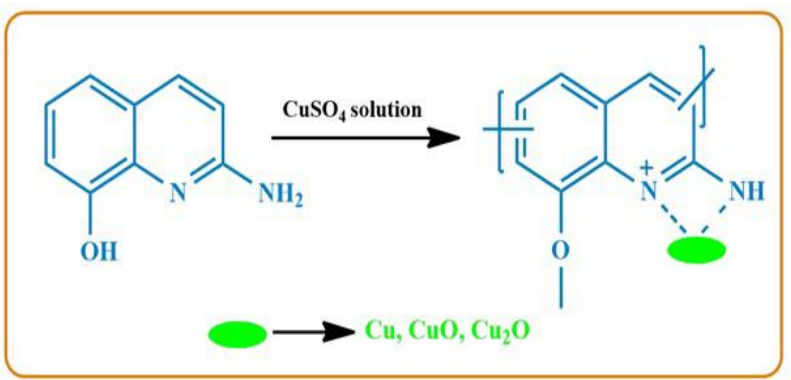

Figure 1. The synthetic procedure for synthesis of $\mathrm{AQP} / \mathrm{Cu}$.

The structure and thermal properties of oxidation product were identified by UV-Vis, FTIR, and TG analysis whereas the morphology is revealed by SEM, TEM analysis. SEM images of oxidation product are given in Figure 2.
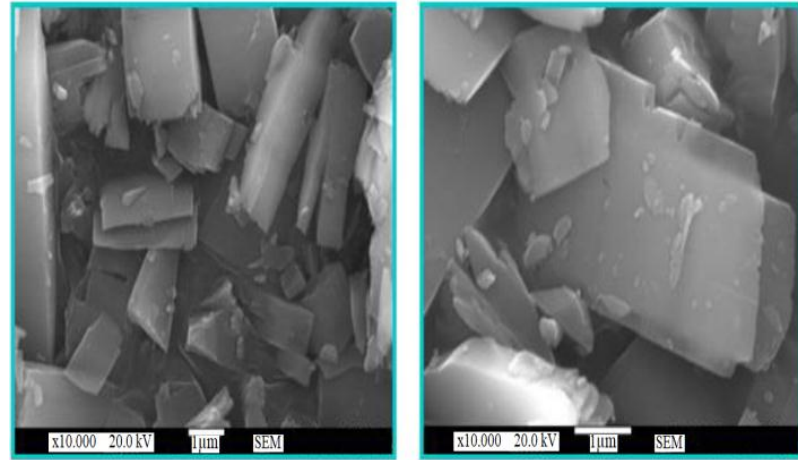

Figure 2. SEM images of $A Q P / C u$. In the left figure, bar shows $1 \mu \mathrm{m}$ (with 10000 magnifications and in the right figure, bar shows $1 \mu \mathrm{m}$ (with 10000 magnification).

Irregular shaped, heterogeneous and micro-sized platelike structures were observed from this Figure. EDX analysis assigned the existence of copper, carbon, nitrogen and sulfur atoms on the surface of the product (Figure 3).

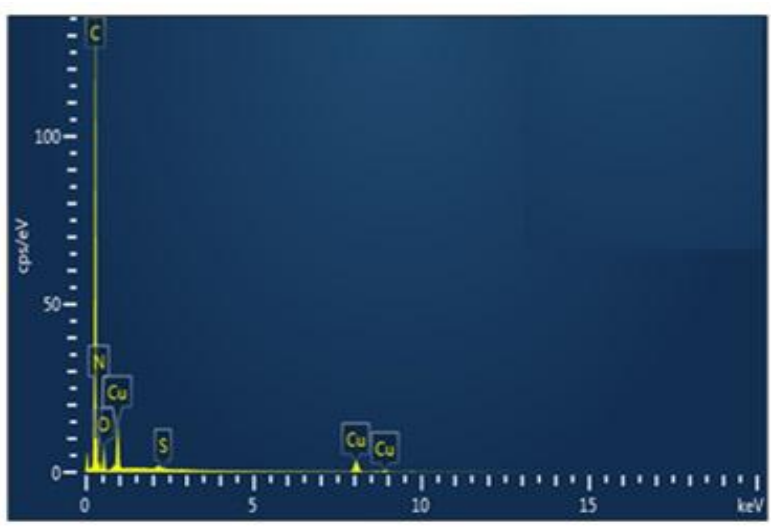

Figure 3. EDX spectrum of $\mathrm{AQP} / \mathrm{Cu}$.

TEM images, given in Figure 4, clearly showed that submicron copper particles were embedded in the rod like polymer structure.
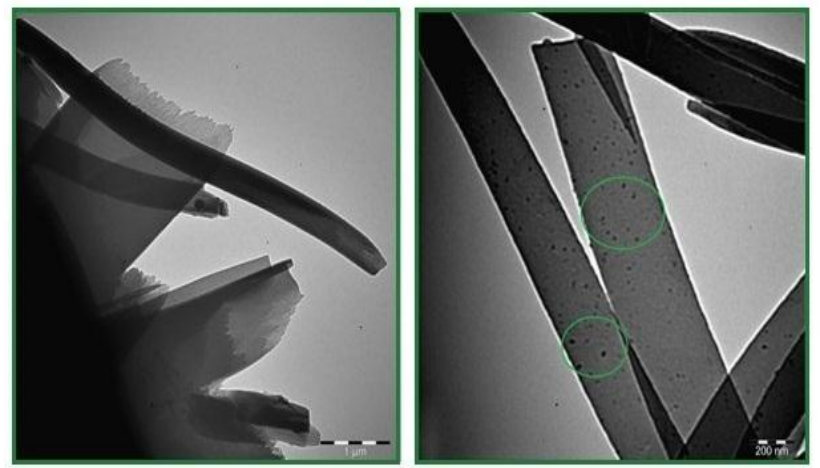

Figure 4. TEM images of $\mathrm{AQP} / \mathrm{Cu}$. In the left figure, bar shows $1 \mu \mathrm{m}$ and in the right figure, bar shows $200 \mathrm{~nm}$.

This morphology is different from previous studies $[6,7,9]$. The thickness and the length of rods observed at Figure 4 were around 200-400 nm, 4-6 $\mu \mathrm{m}$, respectively. 
FTIR spectra of resultant and starting material are given in Figure 5.

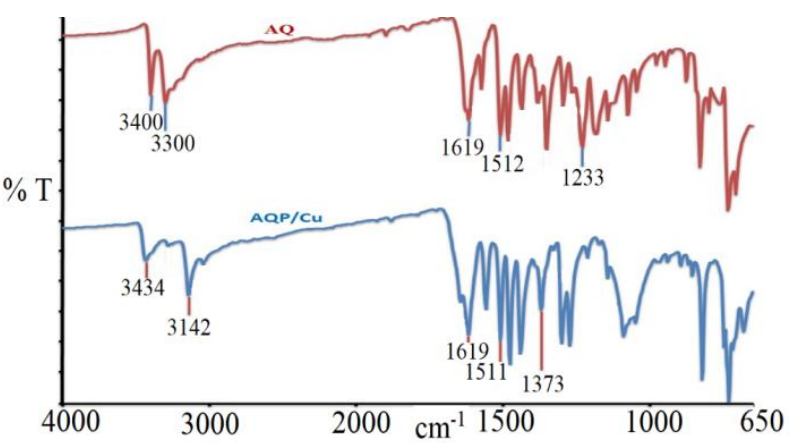

Figure 5. FTIR spectra of $A Q$ and $A Q P / C u$.

The characteristic benzenoid and quinoid vibrations were observed at 1619 and $1511 \mathrm{~cm}^{-1}$. The peak at $1275 \mathrm{~cm}^{-1}$ was also observed possibly due to $\mathrm{C}-\mathrm{N}$ stretching vibration [7]. In addition, the peak observed at $1373 \mathrm{~cm}$ ${ }^{1}$ with medium intensity was assigned to $\mathrm{C}-\mathrm{N}$ stretching for quinoid ring and harmony with literature [7]. Figure 6 exhibits the UV-Vis spectra of AQ and AQP/Cu in DMSO.



Figure 6. UV-Vis spectra of $A Q$ and $A Q P / C u$.

One absorption maximum was recorded (at $350 \mathrm{~nm}$ ) for DMSO solution of AQ. This absorption was attributed to $\pi-\pi$ transition. However, AQP/Cu was characterized by three absorption maxima observed at $308,352(\pi-\pi$ transitions) and $402 \mathrm{~nm}$ ( $\mathrm{n}-\pi$ transition). As a result of oxidation reaction, a red-shifted spectrum was recorded for product obtained. An absorption edge around $445 \mathrm{~nm}$ was observed for $A Q P / C u$. The optical band gaps $\left(E_{o p}\right)$ of $\mathrm{AQ}$ and $\mathrm{AQP} / \mathrm{Cu}$ were measured as given in the literature [12] using $E_{o p}=1240 / \lambda$ equation and found to be 3.27 and $2.82 \mathrm{eV}$, respectively. As known, the quinoline monomer and polymers exhibit interesting optical properties [2]. Therefore, the fluorescence properties of oxidation product were also studied in here. Figure 7 shows the photographs of AQP/Cu solutions (in toluene and DMSO) recorded under $365 \mathrm{~nm}$ UV lamp.

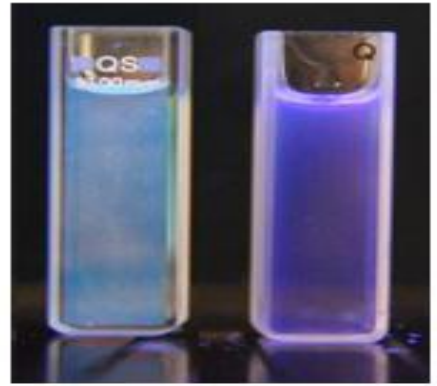

Figure 7. The photographs of $\mathrm{AQP} / \mathrm{Cu}$ solution in toluene (left) and in DMSO (right). The solution was irritated with UV lamp (365 nm).

As seen from Figure 7, toluene and DMSO solutions of $\mathrm{AQP} / \mathrm{Cu}$ were blue (turquoise) and purple colored, respectively. The oxidation of 6AQ with copper sulphate solution was accomplished in our previous work and the similar results were obtained [9].The fluorescence spectra of $\mathrm{AQP} / \mathrm{Cu}$ were obtained in four different solvents (Figure 8).

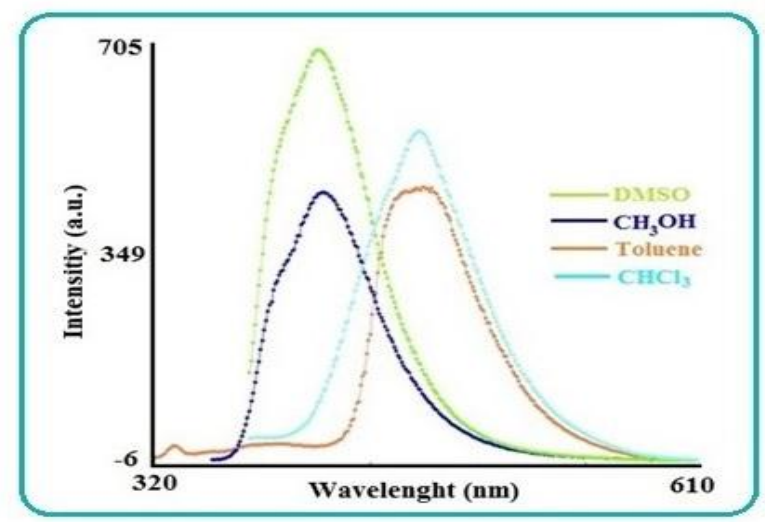

Figure 8. Fluorescence spectra of $\mathrm{AQP} / \mathrm{Cu}$ recorded in different solvents.

As seen from Figure 8, DMSO and methanol solutions of $\mathrm{AQP} / \mathrm{Cu}$ exhibited emission maxima about $410 \mathrm{~nm}$ as excited at $295 \mathrm{~nm}$. However, in the toluene and chloroform solutions of $\mathrm{AQP} / \mathrm{Cu}$ exhibited an emission about $470 \mathrm{~nm}$ when excited at same wavelength. The solid state conductivity measurements of $\mathrm{AQP} / \mathrm{Cu}$ were conducted using four-point probe technique. Before measurements, the sample was doped with iodine vapour for 24 hours and the oxidation product exhibited a conductivity value with $8 \times 10^{-9} \mathrm{Scm}^{-1}$.

\subsection{Thermal decomposition kinetics of $\mathrm{AQP} / \mathrm{Cu}$}

In this section of study, thermal decomposition kinetics of $\mathrm{AQP} / \mathrm{Cu}$ is presented. For a kinetic evaluation, integral conversional methods were used. For determination of kinetic parameters, methods including Flynn-WallOzawa (FWO), Kissinger-Akahira-Sunose (KAS), Tang and also Coats-Redfern (CR) were used. A two-stage decomposition was observed from DTG curve of composite. The temperatures related to the solid state decomposition rates were at 275 (for first decomposition 
stage) and $325^{\circ} \mathrm{C}$ (for second decomposition stage). The 20 and $50 \%$ decompositions of AQP/Cu were observed at 265 and $396^{\circ} \mathrm{C}$, respectively. The residue at $1000^{\circ}$ was $29 \%$ (for heating rate of $5^{\circ} \mathrm{C} \mathrm{min}^{-1}$ ). TGA thermograms recorded at heating rates of $5,10,15$ and $20^{\circ} \mathrm{C} \mathrm{min}-1$ are given in Figure 9. TG curves exhibited the similar decomposition character. As seen from this figure, the curves were slightly shifted to right as the heating rates increased.

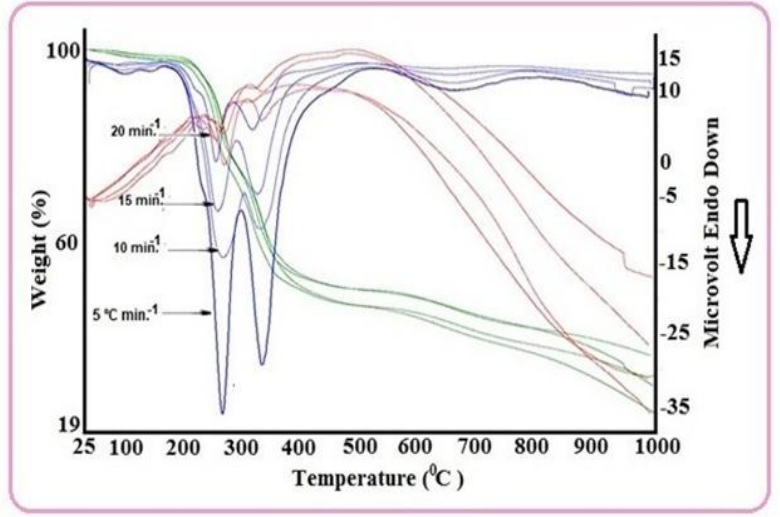

Figure 9. TG-DTG-DTA curves of AQP/Cu obtained in four different heating rates.

Although the apparent kinetic parameters including activation energy, E, and frequency factor A are often determined by nonisothermal methods, International Congress On Thermal Analysis and Calorimetry (ICTAC) purposes the use of the isoconversional methods for calculation of Arrhenius parameters[13]. Therefore, in here, FWO [14,15], Tang [16] and KAS $[17,18]$ procedures were conducted to determine these kinetic parameters. The mathematical equations for these methods (and also for CR [19]) are given in follows:

Tang method

$\ln \left[\beta / T^{1.894661}\right]=\ln [\mathrm{AE} / \operatorname{Rg}(\alpha)]+3.635011-1.894661 \operatorname{lnE}-$

[1.001450E/RT]

KAS method

$\ln \left[\beta / \mathrm{T}^{2}\right]=\ln [\mathrm{AE} / \operatorname{Rg}(\alpha)]-[\mathrm{E} / \mathrm{RT}]$

FWO method

$\log \beta=\log [\mathrm{AE} / \mathrm{R}]-\log \mathrm{g}(\alpha)-2.315-0.4567 \mathrm{E} / \mathrm{RT}$

CR method

$\ln \left[\mathrm{g}(\alpha) / \mathrm{T}^{2}\right]=\ln [\mathrm{AR} / \mathrm{E} \beta]-[\mathrm{ERT}]$

The terms given in equations 3.1-3.4, are $\alpha$ (degree of reaction), $g(\alpha)$ (integral function of conversion), $\beta$ (heating rate), T (DTG peak temperature corresponding maximum decomposition rate) $\mathrm{E}$, activation energy $(\mathrm{kJ}$ mol $\left.^{-1}\right)$, A, pre-exponential factor $\left(\mathrm{s}^{-1}\right)$ and $\mathrm{R}$ gas constant $\left(8.314 \mathrm{~kJ} \mathrm{~mol}^{-1}\right)$. The first method applied for determination of $\mathrm{E}$ parameter (apparent activation energy) is that of Tang. According to this method, E is determined by solution of equation (3.1). E value can be found from a plot of $\log \beta$ versus 1000/T graph. As seen Figure 9, the composite was decomposed in two steps. Therefore, E values were calculated for each decomposition steps and the mean activation energies determined for first and second decomposition steps were 116.6 and $129.9 \mathrm{~kJ} \mathrm{~mol}^{-1}$, respectively.

The E values determined for each decomposition steps, in 0.05-0.95 conversion range, are given Table 1 and Table 2, respectively.

Table 1. Activation energies determined by KAS, FWO and Tang methods for the first decomposition step of $\mathrm{AQP} / \mathrm{Cu}$.

\begin{tabular}{ccccccc}
\hline & KAS & \multicolumn{3}{c}{ Tang } & \multicolumn{2}{c}{ FWO } \\
\hline$\alpha$ & $E$ & $r$ & $E$ & $r$ & $E$ & $\mathrm{r}$ \\
\hline 0.05 & 84.50 & 0.9889 & 86.36 & 0.9982 & 88.86 & 0.9987 \\
0.1 & 86.82 & 0.9983 & 87.54 & 0.9894 & 89.74 & 0.9993 \\
0.2 & 124.4 & 0.9974 & 125.7 & 0.9891 & 126.6 & 0.9984 \\
0.3 & 126.3 & 0.9987 & 125.5 & 0.9996 & 128.5 & 0.9986 \\
0.4 & 127.2 & 0.9977 & 126.6 & 0.9991 & 129.4 & 0.9971 \\
0.5 & 128.1 & 0.9977 & 127.5 & 0.9897 & 129.8 & 0.9963 \\
0.6 & 123.7 & 0.9982 & 124.6 & 0.9898 & 126.3 & 0.9952 \\
0.7 & 125.6 & 0.9963 & 126.1 & 0.9896 & 127.4 & 0.9956 \\
0.8 & 127.2 & 0.9976 & 126.7 & 0.9985 & 128.7 & 0.9962 \\
0.9 & 130.4 & 0.9898 & 132.3 & 0.9889 & 133.6 & 0.9981 \\
0.95 & 92.62 & 0.9899 & 94.78 & 0.9987 & 96.67 & 0.9987 \\
Mean & 116.0 & & 116.6 & & 118.6 & \\
\hline
\end{tabular}

Table 2. Activation energies determined by KAS, FWO and Tang methods for the second decomposition step of $\mathrm{AQP} / \mathrm{Cu}$.

\begin{tabular}{cclclcl}
\hline & KAS & \multicolumn{2}{c}{ Tang } & \multicolumn{2}{c}{ FWO } \\
\hline$\alpha$ & $E$ & $r$ & $E$ & $r$ & $E$ & $r$ \\
\hline 0.05 & 94.78 & 0.9878 & 97.78 & 0.9783 & 98.6 & 0.9882 \\
0.1 & 103.1 & 0.9889 & 106.5 & 0.9894 & 108.4 & 0.9889 \\
0.2 & 134.6 & 0.9892 & 136.4 & 0.9891 & 137.8 & 0.9891 \\
0.3 & 135.4 & 0.9994 & 137.8 & 0.9897 & 138.6 & 0.9892 \\
0.4 & 134.1 & 0.9897 & 138.6 & 0.9998 & 139.4 & 0.9894 \\
0.5 & 135.8 & 0.9894 & 136.7 & 0.9895 & 138.7 & 0.9891 \\
0.6 & 137.3 & 0.9893 & 138.5 & 0.9891 & 139.6 & 0.9891 \\
0.7 & 133.5 & 0.9893 & 135.6 & 0.9893 & 137.7 & 0.9988 \\
0.8 & 136.6 & 0.9992 & 138.1 & 0.9895 & 139.7 & 0.9990 \\
0.9 & 134.5 & 0.9988 & 136.0 & 0.9983 & 139.6 & 0.9982 \\
0.95 & 126.7 & 0.9989 & 127.8 & 0.9982 & 129.4 & 0.9984 \\
Mean & 127.8 & & 129.9 & & 131.5 & \\
\hline
\end{tabular}

The second method studied in here is that of KAS. In this method, E is determined by solution of equation (3.2) and obtained from plots of $\ln \left[\beta / \mathrm{T}^{2}\right]$ against $1 / \mathrm{T}$ graph (for a wide range of conversions). From resulting graph, E values were found to be 116.0 (for first decomposition step) and $127.8 \mathrm{~kJ} \mathrm{~mol}^{-1}$ (for second decomposition step). 
The E values determined for each decomposition steps are given Table 1 and Table 2, respectively. The third method applied for determination of $\mathrm{E}$ is that of FWO (Eq. 3.3). In this method, $\mathrm{E}$ is determined by solution of equation (3.3). From slope of $\ln \beta$ versus 1000/T graph, $\mathrm{E}$ values can be determined for different conversions values. E values calculated for first and second decomposition steps were 118.6 and $131.5 \mathrm{~kJ} \mathrm{~mol}^{-1}$, respectively. $\mathrm{E}$ values determined for each decomposition step, in different conversion range, are presented Table 1 and 2, respectively. As seen these results, E values obtained by three different methods are close to each other for different conversion ranges. $\mathrm{E}$ values obtained by Tang, KAS and FWO methods were 116.6, 116.0 and $118.6 \mathrm{~kJ} \mathrm{~mol}^{-1}$ (first decomposition step) and 129.9, 127.8 and $131.5 \mathrm{~kJ} \mathrm{~mol}^{-1}$ (second decomposition step), respectively. The last method used in this study is that of CR (equation (3.4)) [19]. CR is a integral method based on single heating rate. Besides kinetic parameters, the thermal decomposition mechanism can be also found using this method. The mathematical functions used in solid state decomposition processes are given in Table 3 [20]. In this method, E values were obtained from solution of Equation 3.4. From slope of $\ln \left[\mathrm{g}(\alpha) / \mathrm{T}^{2}\right]$ against 1000/T graph, E values can be found. $\mathrm{E}$ values calculated for a four different heating $\left(5,10,15\right.$ and $20{ }^{\circ} \mathrm{C} \mathrm{min}-1$ under a nitrogen atmosphere) for both first and second decomposition steps were presented in Table 4 and Table 5.

Table 3. Mathematical functions used in solid state decomposition processes.

\begin{tabular}{|c|c|c|c|c|}
\hline No & Mechanism & Symbol & Differential form, $f(\alpha)$ & Integral form $g(\alpha)$ \\
\hline \multicolumn{5}{|c|}{ Sigmoidal curves } \\
\hline 1 & $\mathrm{~N}$ and $\mathrm{G}(\mathrm{n}=1)$ & $\mathrm{A}_{1}$ & $(1-\alpha)$ & {$[-\ln (1-\alpha)]$} \\
\hline 2 & $\mathrm{~N}$ and $\mathrm{G}(\mathrm{n}=1.5)$ & $\mathrm{A}_{1.5}$ & $(3 / 2)(1-\alpha)[-\ln (1-\alpha)]^{1 / 3}$ & {$[-\ln (1-\alpha)]^{2 / 3}$} \\
\hline 3 & $\mathrm{~N}$ and $\mathrm{G}(\mathrm{n}=2)$ & $\mathrm{A}_{2}$ & $2(1-\alpha)[-\ln (1-\alpha)]^{1 / 2}$ & {$[-\ln (1-\alpha)]^{1 / 2}$} \\
\hline 4 & $\mathrm{~N}$ and $\mathrm{G}(\mathrm{n}=3)$ & $\mathrm{A}_{3}$ & $3(1-\alpha)[-\ln (1-\alpha)]^{2 / 3}$ & {$[-\ln (1-\alpha)]^{1 / 3}$} \\
\hline 5 & $\mathrm{~N}$ and $\mathrm{G}(\mathrm{n}=4)$ & $\mathrm{A}_{4}$ & $4(1-\alpha)[-\ln (1-\alpha)]^{3 / 4}$ & {$[-\ln (1-\alpha)]^{1 / 4}$} \\
\hline \multicolumn{5}{|c|}{ Deceleration curves } \\
\hline 6 & Diffusion, 1D & $\mathrm{D}_{1}$ & $1 /(2 \alpha)$ & $\alpha^{2}$ \\
\hline 7 & Diffusion, 2D & $\mathrm{D}_{2}$ & $1 /(\ln (1-\alpha))$ & $(1-\alpha) \ln (1-\alpha)+\alpha$ \\
\hline 8 & Diffusion, 3D & $\mathrm{D}_{3}$ & $1.5 /\left[(1-\alpha)^{-1 / 3}-1\right]$ & $(1-2 \alpha / 3)-(1-\alpha)^{2 / 3}$ \\
\hline 9 & Diffusion, 3D & $\mathrm{D}_{4}$ & {$\left[1.5(1-\alpha)^{2 / 3}\right]\left[1-(1-\alpha)^{1 / 3}\right]^{-1}$} & {$\left[1-(1-\alpha)^{1 / 3}\right]^{2}$} \\
\hline 10 & Diffusion, 3D & $\mathrm{D}_{5}$ & $(3 / 2)(1+\alpha)^{2 / 3}\left[(1+\alpha)^{1 / 3}-1\right]^{-1}$ & {$\left[(1+\alpha)^{1 / 3}-1\right]^{2}$} \\
\hline 11 & Diffusion, 3D & $\mathrm{D}_{6}$ & $(3 / 2)(1-\alpha)^{4 / 3}\left[\left[1 /(1-\alpha)^{1 / 3}\right]-1\right]^{-1}$ & {$\left[[1 /(1-\alpha)]^{1 / 3}-1\right]^{2}$} \\
\hline 12 & $\begin{array}{l}\text { Contracted geometry shape } \\
\text { (cylindrical symmetry) }\end{array}$ & $\mathrm{R}_{2}$ & $3(1-\alpha)^{2 / 3}$ & $1-(1-\alpha)^{1 / 3}$ \\
\hline 13 & $\begin{array}{l}\text { Contracted geometry shape } \\
\text { (sphere symmetry) }\end{array}$ & $\mathrm{R}_{3}$ & $3(1-\alpha)^{2 / 3}$ & $1-(1-\alpha)^{1 / 3}$ \\
\hline \multicolumn{5}{|c|}{ Acceleration curves } \\
\hline 14 & Mample power law & $\mathrm{P}_{1}$ & 1 & $\mathrm{~A}$ \\
\hline 15 & Mample power law $(n=2)$ & $\mathrm{P}_{2}$ & $2 \alpha^{1 / 2}$ & $\alpha^{1 / 2}$ \\
\hline 16 & Mample power law $(n=3)$ & $\mathrm{P}_{3}$ & $(1.5) \alpha^{2 / 3}$ & $\alpha^{1 / 3}$ \\
\hline 17 & Mample power law $(n=4)$ & $\mathrm{P}_{4}$ & $4 \alpha^{3 / 4}$ & $\alpha^{1 / 4}$ \\
\hline 18 & Mample power law $(n=2 / 3)$ & $\mathrm{P}_{3 / 2}$ & $2 / 3(\alpha)^{-1 / 2}$ & $\alpha^{3 / 2}$ \\
\hline 19 & Mample power law $(n=3 / 2)$ & $\mathrm{P}_{2 / 3}$ & $3 / 2(\alpha)^{1 / 3}$ & $\alpha^{2 / 3}$ \\
\hline 20 & Mample power law $(n=4 / 3)$ & $\mathrm{P}_{3 / 4}$ & $4 / 3(\alpha)^{-1 / 3}$ & $\alpha^{3 / 4}$ \\
\hline
\end{tabular}

Table 4 .The activation energies obtained for the first decomposition step of AQP/Cu by the CR method in the nitrogen atmosphere.

\begin{tabular}{|c|c|c|c|c|c|c|c|c|}
\hline \multicolumn{3}{|c|}{$5^{\circ} \mathrm{C} \mathrm{min}^{-1}$} & \multicolumn{2}{|c|}{$10^{\circ} \mathrm{C} \mathrm{min}-1$} & \multicolumn{2}{|c|}{$15^{\circ} \mathrm{C} \mathrm{min}^{-1}$} & \multicolumn{2}{|c|}{$20^{\circ} \mathrm{C} \mathrm{min}^{-1}$} \\
\hline & $\begin{array}{c}E \\
\left(\mathrm{~kJ} \mathrm{~mol}^{-1}\right)\end{array}$ & $r$ & $\begin{array}{c}E \\
\left(\mathrm{~kJ} \mathrm{~mol}^{-1}\right)\end{array}$ & $r$ & $\begin{array}{c}E \\
\left(\mathrm{~kJ} \mathrm{~mol}^{-1}\right)\end{array}$ & $r$ & $\begin{array}{c}E \\
\left(\mathrm{~kJ} \mathrm{~mol}^{-1}\right)\end{array}$ & $r$ \\
\hline $\mathrm{A}_{1}$ & 50.6 & 0.96784 & 52.2 & 0.96878 & 52.6 & 0.96788 & 53.6 & 0.96886 \\
\hline $\mathrm{A}_{1,5}$ & 48.0 & 0,96766 & 49.4 & 0,96676 & 49.6 & 0,96777 & 40.6 & 0,96677 \\
\hline $\mathrm{A}_{2}$ & 26.6 & 0.98327 & 28.4 & 0.98632 & 29.0 & 0.98374 & 29.4 & 0.97831 \\
\hline $\mathrm{A}_{3}$ & 15.8 & 0.97845 & 15. & 0.97864 & 16.1 & 0.97881 & 17.7 & 0.97786 \\
\hline $\mathrm{A}_{4}$ & 20.2 & 0.98878 & 21.6 & 0.98876 & 21.0 & 0.98817 & 22.6 & 0.97888 \\
\hline $\mathrm{D}_{1}$ & 80.9 & 0.97881 & 81.6 & 0.97687 & 82.5 & 0.97881 & 83.0 & 0.98787 \\
\hline
\end{tabular}




\begin{tabular}{lcccccccc}
$\mathrm{D}_{2}$ & 100. & 0.98924 & 102.9 & 0.98692 & 104.7 & 0.98971 & 105.6 & 0.97890 \\
$\mathrm{D}_{3}$ & 115.2 & 0.97927 & 114.2 & 0.97692 & 114.9 & 0.97911 & 115.8 & 0.98791 \\
$\mathrm{D}_{4}$ & 122.5 & 0.98886 & 122.1 & 0.98688 & 124.8 & 0.98886 & 124.3 & 0.97881 \\
$\mathrm{D}_{5}$ & 92.7 & 0.98917 & 93.4 & 0.98791 & 93.7 & 0.98964 & 94.6 & 0.98892 \\
$\mathrm{D}_{6}$ & 143.8 & 0.98966 & 144.5 & 0.98696 & 145.2 & 0.98912 & 143.5 & 0.98896 \\
$\mathrm{R}_{2}$ & 56.0 & 0.98878 & 56.2 & 0.98887 & 57.4 & 0.98874 & 57.9 & 0.98886 \\
$\mathrm{R}_{3}$ & 63.9 & 0.98729 & 64.4 & 0.98872 & 65.0 & 0.98786 & 65.6 & 0.97877 \\
$\mathrm{P}_{1}$ & 51.1 & 0.97887 & 52.5 & 0.97888 & 52.2 & 0.97888 & 53.1 & 0.97781 \\
$\mathrm{P}_{2}$ & 27.8 & 0.98851 & 27.8 & 0.98885 & 28.2 & 0.98842 & 18.2 & 0.98880 \\
$\mathrm{P}_{3}$ & 10.6 & 0.98840 & 10.6 & 0.98884 & 10.6 & 0.98878 & 10.4 & 0.98887 \\
$\mathrm{P}_{4}$ & 6.6 & 0.97820 & 6.5 & 0.97882 & 6.6 & 0.97876 & 6.6 & 0.98781 \\
$\mathrm{P}_{3 / 2}$ & 76.8 & 0.98862 & 77.1 & 0.98986 & 77.8 & 0.98861 & 78.8 & 0.98888 \\
$\mathrm{P}_{2 / 3}$ & 45.9 & 0.97854 & 46.1 & 0.97784 & 46.6 & 0.97887 & 46.4 & 0.98782 \\
$\mathrm{P}_{3 / 4}$ & 59.7 & 0.96876 & 50.2 & 0.96786 & 50.6 & 0.9686 & 50.6 & 0.97681 \\
\hline
\end{tabular}

Table 5 . The activation energies obtained for the second decomposition step of AQP/Cu by the CR method in the nitrogen atmosphere.

\begin{tabular}{|c|c|c|c|c|c|c|c|c|}
\hline \multicolumn{3}{|c|}{$\underline{5^{\circ} \mathrm{C} \min ^{-1}}$} & \multicolumn{2}{|c|}{$10^{\circ} \mathrm{C} \mathrm{min}^{-1}$} & \multicolumn{2}{|c|}{$15^{\circ} \mathrm{C} \mathrm{min}^{-1}$} & \multicolumn{2}{|c|}{$20{ }^{\circ} \mathrm{C} \min ^{-1}$} \\
\hline & $\begin{array}{c}E \\
\left(\mathrm{~kJ} \mathrm{~mol}^{-1}\right)\end{array}$ & $r$ & $\begin{array}{c}E \\
\left(\mathrm{~kJ} \mathrm{~mol}^{-1}\right)\end{array}$ & $r$ & $\begin{array}{c}E \\
\left(\mathrm{~kJ} \mathrm{~mol}^{-1}\right)\end{array}$ & $r$ & $\begin{array}{c}E \\
\left(\mathrm{~kJ} \mathrm{~mol}^{-1}\right)\end{array}$ & $r$ \\
\hline $\mathrm{A}_{1}$ & 44.0 & 0.98834 & 41.1 & 0.99812 & 43.6 & 0.99843 & 43.8 & 0.99842 \\
\hline $\mathrm{A}_{1,5}$ & 29.1 & 0.98845 & 28.2 & 0.98813 & 29.4 & 0.98965 & 28.6 & 0.98932 \\
\hline $\mathrm{A}_{2}$ & 22.4 & 0.98687 & 22.6 & 0.98775 & 22.7 & 0.98592 & 27.2 & 0.98597 \\
\hline $\mathrm{A}_{3}$ & 15.2 & 0.98658 & 14.1 & 0.98336 & 14.9 & 0.98579 & 14.4 & 0.98429 \\
\hline $\mathrm{A}_{4}$ & 2.7 & 0.99895 & 2.1 & 0.99811 & 2.2 & 0.98854 & 2.3 & 0.98872 \\
\hline $\mathrm{D}_{1}$ & 90.1 & 0.98886 & 90.6 & 0.98960 & 91.7 & 0.98841 & 90.8 & 0.98834 \\
\hline $\mathrm{D}_{2}$ & 108.9 & 0.98789 & 108.9 & 0.98897 & 109.4 & 0.98083 & 108.7 & 0.98685 \\
\hline $\mathrm{D}_{3}$ & 111.8 & 0.98767 & 112.5 & 0.98129 & 112.6 & 0.98788 & 112.8 & 0.98228 \\
\hline $\mathrm{D}_{4}$ & 127.7 & 0.98848 & 128.9 & 0.98801 & 128.0 & 0.98854 & 127.7 & 0.97874 \\
\hline $\mathrm{D}_{5}$ & 146.2 & 0.99818 & 147.5 & 0.99822 & 147.7 & 0.99823 & 148.2 & 0.98775 \\
\hline $\mathrm{D}_{6}$ & 158.8 & 0.99371 & 158.9 & 0.99482 & 159.2 & 0.99683 & 159.6 & 0.99578 \\
\hline $\mathrm{R}_{2}$ & 46.9 & 0.98797 & 47.0 & 0.98418 & 47.2 & 0.98718 & 64.4 & 0.98472 \\
\hline $\mathrm{R}_{3}$ & 49.7 & 0.98883 & 50.1 & 0.97845 & 50.2 & 0.9823 & 50.5 & 0.98767 \\
\hline $\mathrm{P}_{1}$ & 21.0 & 0.98768 & 21.0 & 0.98765 & 22.6 & 0.97711 & 22.2 & 0.98776 \\
\hline $\mathrm{P}_{2}$ & 15.1 & 0.98579 & 15.1 & 0.98276 & 16.1 & 0.98743 & 17.1 & 0.98787 \\
\hline $\mathrm{P}_{3}$ & 10.7 & 0.98447 & 11.7 & 0.98437 & 12.4 & 0.98273 & 12.7 & 0.98874 \\
\hline $\mathrm{P}_{4}$ & 12.0 & 0.98821 & 12.4 & 0.98865 & 12.6 & 0.98247 & 12.8 & 0.98680 \\
\hline $\mathrm{P}_{3 / 2}$ & 46.7 & 0.98862 & 47.2 & 0.98813 & 47.4 & 0.97977 & 48.6 & 0.98768 \\
\hline $\mathrm{P}_{2 / 3}$ & 20.6 & 0.98574 & 21.7 & 0.98482 & 22.7 & 0.98832 & 22.8 & 0.98883 \\
\hline $\mathrm{P}_{3 / 4}$ & 23.4 & 0.98776 & 23.6 & 0.98148 & 23.4 & 0.98564 & 23.8 & 0.98787 \\
\hline
\end{tabular}

From these data, it was found that the most suitable decomposition mechanism for the first decomposition step of composite $\left(20^{\circ} \mathrm{C} \mathrm{min}{ }^{-1}\right)$ was $\mathrm{D}_{3}$. However, $\mathrm{D}_{4}$ was determined as the most suitable mechanism for the second decomposition step $\left(10^{\circ} \mathrm{C} \mathrm{min}^{-1}\right)$.

\section{Conclusion}

The results of this study showed that the copper sulphate solution could effectively oxidize AQ in ambient conditions. As a result of oxidation reaction, a composite product composed of quinoline polymer and copper particles was obtained. TEM images assigned that submicron copper particles were dispersed on the rod like polymer structure. The composite was decomposed in two main decomposition steps. These decomposition steps were kinetically analyzed. For a kinetic evaluation,
FWO, KAS, Tang and CR methods were used. E values obtained by Tang, KAS and FWO method were found to be 116.6, 116.0, and $118.6 \mathrm{~kJ} \mathrm{~mol}^{-1}$ for first decomposition stage and 129.9, 127.8 and $131.5 \mathrm{~kJ} \mathrm{~mol}^{-}$ ${ }^{1}$ for the second decomposition stage, respectively. For determination of decomposition mechanism of composite, CR method was also studied and Dn type mechanism was suggested for each decomposition step.

\section{Acknowledgements}

This study is financially supported by Çanakkale Onsekiz Mart University Scientific Research Project Coordination Unit (Project number: FBA-2014-288). 


\section{References}

1. Stille, J.K, Polyquinolines, Macromolecules, 1981, 14(3), 870880 .

2. Kimyonok, A, Wang, X.Y, Weck, M, Electroluminescent poly(quinoline)s and metalloquinolates, Journal Macromolecular Science Part C Polymer Reviews, 2006, 46 (1), 47-77.

3. Thivaios, I, Koukoumtzis, V, Kallitsis, J.K, Bokias, G, Quinolinelabeled poly(N-isopropylacrylamide): a selective polymeric luminescent sensor of cationic surfactants, Sensors and Actuators $B, 2016,233,127-135$.

4. Bilici, A, Chemical oxidation of 5-amino quinoline with $\left(\mathrm{NH}_{4}\right)_{2} \mathrm{~S}_{2} \mathrm{O}_{8}$ : synthesis and characterization, Hacettepe Journal of Biology and Chemistry, 2017, 45, 563-571.

5. Yu, L, Han, Z, Ding, Y, Gram-scale preparation of Pd@PANI: a practical catalyst reagent for copper-free and ligand-free Sonogashira couplings, Organic Process Research \& Development, 2016, 20 (12), 2124-2129.

6. Islam, R.U, Mahato, S.K, Shukla, S.K, Witcomb, M.J, Mallick, K Palladium-poly(3-aminoquinoline) hollow-sphere composite: application in Sonogashira coupling reactions, ChemCatChem, 2013, 5 (8), 2453-2461

7. Choudhary, M, Islam, R.U, Witcom, M.J, Phali, M, Mallick, K, Template-less synthesis of polymer hollow spheres: an efficient catalyst for Suzuki coupling reaction, Applied Organometallic Chemistry, 2013, 27 (9), 523-528.

8. Bilici, A, Ayten, B, Kaya, İ, Facile preparation of gold nanoparticles on the polyquinoline matrix: catalytic performance toward 4-nitrophenol reduction, Synthetic Metals, 2015, 201, 1117.

9. Bilici, A, Tezel, R.N, Kaya, İ, Facile chemical route to copper/polymer composite: simultaneous reduction and polymerization, Colloids and Surfaces A: Physicochemical and Engineering Aspects, 2014, 459 (5), 254-260.

10. Mallick, K, Witcomb, M.J, Scurrell, M.S, In situ synthesis of copper nanoparticles and poly(o-toluidine): a metal-polymer composite material, European Polymer Journal, 2006, 42(3), $670-675$
11. Islam, R.U., Taher, A., Choudhary, M., Siwal, S., Mallick K., Polymer immobilized $\mathrm{Cu}(\mathrm{I})$ formation and azide-alkyne cycloaddition: A one pot reaction, Scientific Reports, 2015, 5, 1-8.

12. Costa, J.C.S, Taveira, R.J.S, Lima, C.F.R.A.C, Mendes, A, Santos L.M.N.B.F, Optical band gaps of organic semiconductor materials, Optical Materials, 2016, 58, 51-60.

13. Vyazovkin, S, Burnham, A.K, Criado, J.M, Pérez-Maqueda, L.A, Popescu C, Sbirrazzuoli, N, ICTAC kinetics committee recommendations for performing kinetic computations on thermal analysis data, Thermochimica Acta, 2011, 520, 1-19.

14. Flynn, J.H, Wall, L.A, A quick, direct method for the determination of activation energy from thermogravimetric data, Journal of Polymer Science Part C: Polymer Letters, 1966, 4 (5), 323-328.

15. Takeo, $\mathrm{O}, \mathrm{A}$ new method of analyzing thermogravimetric data., Bulletin of the Chemical Society of Japan, 1965, 38 (11), 18811886

16. Wanjun, T, Yuwen, L, Xi Y, Cunxin, W, Kinetic studies of the calcination of ammonium metavanadate by thermal methods, Industrial \& Engineering Chemistry Research, 2004, 43 (9), 2054 2059 .

17. Kissinger, H.E, Reaction kinetics in differential thermal analysis, Analytical Chemistry, 1957, 29 (11), 1702-1706.

18. Akahira, $\mathrm{T}$, Sunose, $\mathrm{T}$, Method of determining activation deterioration constant of electrical insulating materials, Research Report Chiba Institute of Technology, 1971, 16, 22-31.

19. Coats, A.W, Redfern, J.P, Kinetics parameters from thermogravimetric data. Nature, 1964, 201, 68-69.

20. Kamel, L.T, The kinetic analysis of non- isothermal carisoprodo reaction in nitrogen atmosphere using the invariant kinetic parameters method, European Journal of Chemistry, 2014, 5 (3), 507- 512 . 